\title{
ROMI-Driven Sales Promotions: How The Biggest Coca-Cola Bottler Outside Of The U.S. Learned How To Measure The Impact Of Their Sales Promotions
}

Nico Schinagl Waller, Universidad Anáhuac del Sur, Mexico

\begin{abstract}
As part of the arsenal of marketing, sales promotions are strategies wherein an incentive is offered to the final consumer or customer to impact sales in the short term (not to exceed three months). Also part of the family are trade promotions that have the same objective, but whose incentives are targeted to the channel of distribution or the POP owners instead of the final consumer.
\end{abstract}

By this definition, one would suppose it is one of the tools of marketing that is the easiest to measure in financial terms because of its short-term nature and specific aim to impact hard metrics, such as sales vs. other campaigns, that try to impact soft metrics, such as brand consideration of purchase intent.

Sadly, as the market study presented indicates, few marketing executives, well knowing the exact costs related in each promotion, bother to estimate the required resulting sales to obtain an attractive return on investment and few and far between do a post-mortem examination to quantify the real returns.

As such, the objective of this paper is to present an easy methodology to evaluate, before and after, in financial terms, sales promotions of all different types and of all verticals, whether they are $B 2 C$ or $B 2 B$.

Also, an in-the-field assessment of the methodology will be presented inside the promotional division of FEMSA, the biggest Coca-Cola Bottler in the world (outside of the US) which performs over 300 promotions per year. The example will serve to illustrate how to implement and replicate this methodology inside of other companies, as well as give evidence of its impact.

Keywords: sales promotion, trade promotions, types of sales promotions, tanbile measurement, ROMI, onpack promotions, in-pack promotions, Coca-Cola marketing

\section{INTRODUCTION}

乌

$\mathrm{n}$ today's marketing environment in which the traditional mass media has already started its decline ${ }^{1}$ with the ever-increasing zapping, the penetration of DVR solutions, and the devastating reality of only a $9 \%$ result in day-after recall surveys of television spots $^{2}$, new and more direct approaches are ever increasingly the focus of the marketing budget.

\footnotetext{
${ }^{1}$ CAPPO, Joe. (2003). "The Future of Advertising." $1^{\text {st }}$ edition. McGraw-Hill. U.S.A.

2 JAFFE, Joseph. (2005). "Life after the 30 second spot: how to energize your brand." Prentice Hall. U.S.A.
} 
In this research, an old and well acquainted tool is sales promotions which target the final consumer (in a B2C environment) or customer (in a B2B environment) with an incentive to impact sales in the short term (not to exceed three months).

Trade promotions, normally targeting the final consumer or customer via the channels of distribution, in the case of $\mathrm{B} 2 \mathrm{C}$, the owners of the point-of-purchase, and in the case of $\mathrm{B} 2 \mathrm{~B}$, the channel partners that promote the company's product or services, is also a well used tool to impact sales.

They are normally considered penetration strategies due to trying to sell more of the same (up-sell) or promoting a new product launch or an extension of an existing product line (cross-sell) to the existing customer base. Some, of course, also have the added benefit of attracting new customers of the mercenary type; i.e., customers with little brand loyalty and easily motivated to temporary switch brands due to a price incentive.

The incentives given normally determine the type of sales promotions, whether it is trying to increase sales via product or a financial benefit. Following is a brief description ${ }^{3}$ of the types of sales promotions:

Product Incentives: In this category, there are three main and highly-used types of sales promotions:

1. On-Pack, easily described as a promotion that puts together two different products, whether from different brands of the company or an extension of a product or service line. Two main objectives besides the desired increase of sales, are to be encountered:

- To support a product or service launch, by giving the existing customer base a chance to try out the new product or service for free, in their regular purchase

- To aid a weak product or service that is currently not obtaining the desired sales levels

2. In-Pack, also easily described as all promotions inside the package (i.e., $20 \%$ additional product for free is a well-known example). It also has secondary objectives, such as:

- To increase the frequency of use or consumption of the existing customer base

$\circ$ To become a temporary bridge in an intended change or upsize of packaging

3. Volume, which, by definition, is a promotion of the same product, but divided in several packages (i.e., the two-for-one promotion is a perfect example). ${ }^{4}$

Financial Incentives: In this category, there are promotions in which the customer or consumer perceives a direct financial gain when entering the promotion:

1. Discounts have been a very traditional mechanism, especially for seasonal items; but there is a trend to minimize these kinds of promotions since they can affect the brand value of the product or service.

2. Contests in which the consumers have a chance to enter a skill-based contest after a random selection of the participants. Often, since the participants-to-be have to send in or register on-line, it is a disguised market research program.

\footnotetext{
${ }^{3}$ It is important to note, that promotions that temporarily ally two or more different brands from different companies, are not called sales promotions, although some of their intended goals are the same, but rather belong to the domain of co-marketing strategies.

${ }^{4}$ There is some debate in the marketing community, since some categorize this type of sales promotion as a financial-incentive based promotion, since some perceive the additional product as just a disguised discount. But for purposes of this paper, we will categorize it under the product-incentive umbrella.
} 
3. Prizes, described by its true random nature, in which a consumer, just by registering its purchase and without any skill, is selected as the winner of the promotion ${ }^{5}$

Trade Promotions: As mentioned, these are directed at the owners of the point-of-purchase (B2C) or the channel members (B2B) $)^{6}$ and are classified as:

1. Communication in which, by a given incentive, the POP owner allows special communication marketing material to be placed in strategic locations

2. Shelf Space in which the POP owner receives, from the company, special shelf space options or designs, such as refrigerators, to be placed in high traffic zones

3. Incentives \& Bonuses where special sales incentives are provided to the external sales force present at the point-of-purchase

Independently of which type, all promotions have, as the main objective, to achieve a temporary rise in sales - called the promotional lift ${ }^{7}$ - compared to the historical trend of sales, called the base line, as illustrated in Graph 1 .

\section{Graph 1: Sales Promotions (December 2007)}

Promotional Lift: the increase of sales achieved and attributed to the sales promotion.

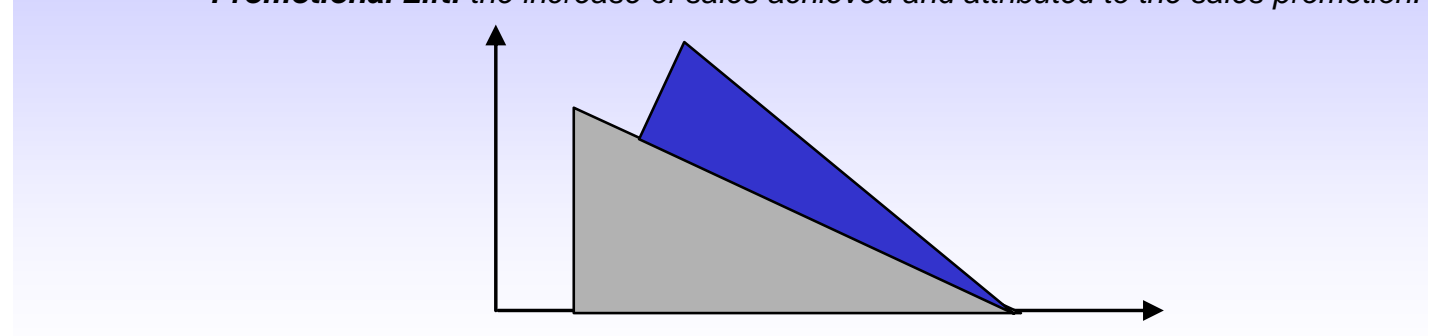

Base Line Sales: historical trend of the sales per period per product.

Any promotion that does not generate this lift is automatically called a failure; but even successful promotions - those that make the objective of creating a promotional lift - can be summed up in three levels, as shown in Graph 2.

\footnotetext{
${ }^{5}$ It is interesting to note, that in several countries tax regulations differ from skill and not skill-based contest. In Mexico for example, if the contest or prize is non-skill based the government intervention represents an $18 \%$ direct tax on the value of the prize. Meanwhile, if the contest includes any form of a skill requirement, an event as simple as posing one single question, the direct tax is reduced to only $6 \%$ of the value of the prize.

${ }^{6}$ BARBER KURI, Carlos Miguel., LOZANO CHÁVEZ, José. (09 de septiembre de 2003). “Implicaciones de Internet y el Intercambio B2B-B2C”. El Financiero. Año XXII. No. 6375. Sección Negocios. P. 30. México.

${ }^{7}$ DAVIS, A. John. (2005). "Magic Numbers for Consumer Marketing." John Wiley \& Sons. U.S.A.
} 


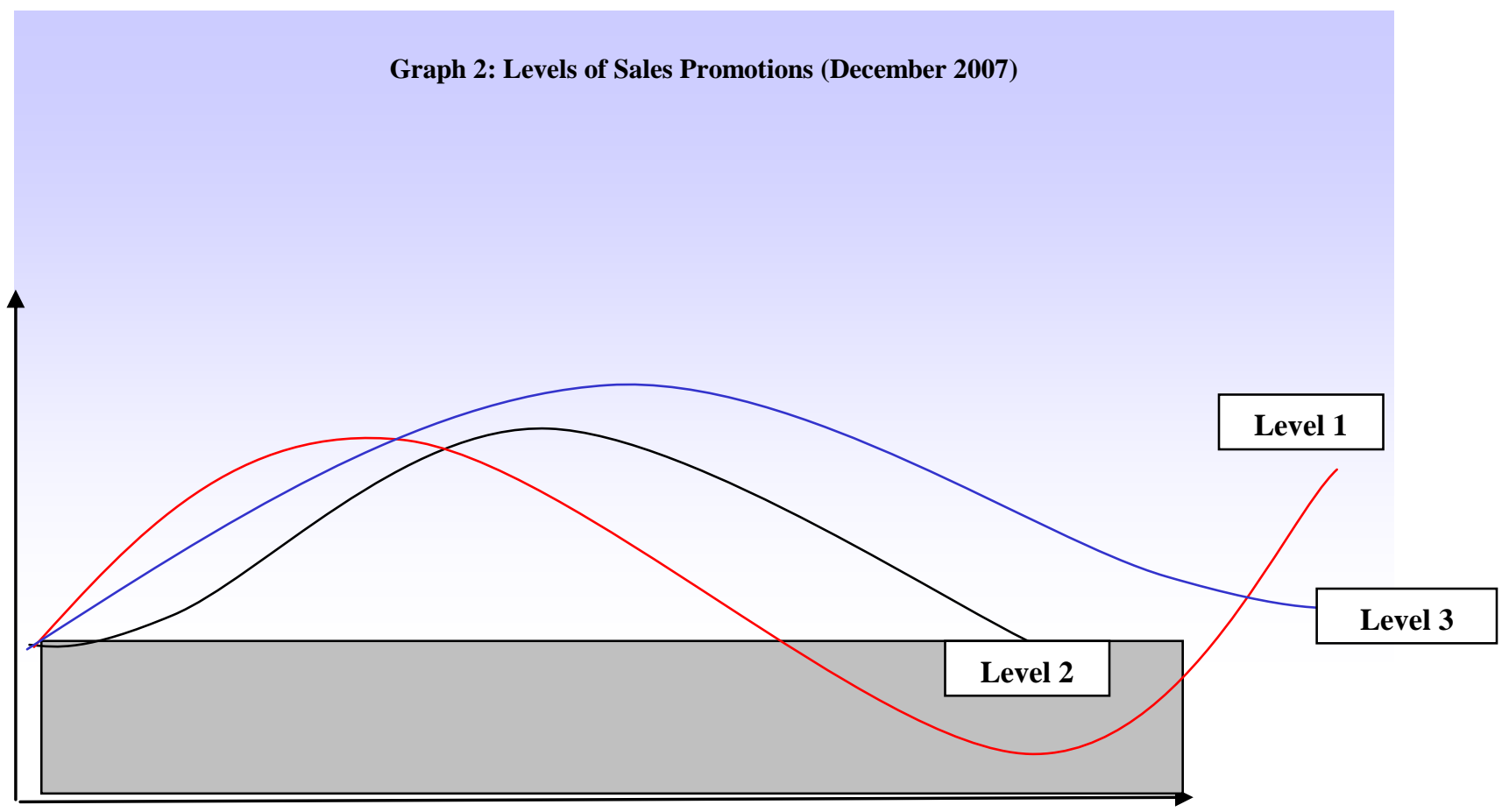

- Level 1: are considered promotions that gain a promotional lift during the campaign, but provoke a negative impact on sales after the promotion expires. Also called the roller-coaster effect, it is often due to the predictable nature of the reoccurring promotion, thus making the savvy customer base await the promotion to stock up on product.

- Level 2: are the promotions that meet their objective of increasing sales, and, after the promotion is over, return to historical base line levels. It is by definition a successful promotion, since it increases sales temporarily without sacrificing future income.

- Level 3: are the champions of promotions, since, not only do they obtain the desired promotional lift, but once the promotion expires, sales stay at higher than base line levels. This is normally achieved, due to the fact, that the promotion brought new customers to the table or increased the frequency of use or consumption of the existing customers ${ }^{8}$.

\section{Market Study}

To determine which sales promotion types are considered to have the most impact on sales, a market research was held, including only marketing managers and brand managers. The total size of the sample represented 112 participants that accounted and controlled yearly marketing budgets of US \$462 million dollars, a signal of the senior level of management included in the survey.

\footnotetext{
${ }^{8}$ No study was found, that has assessed promotions in a serious investigation to quantify how many fall in each of the levels presented.
} 
Graph 3

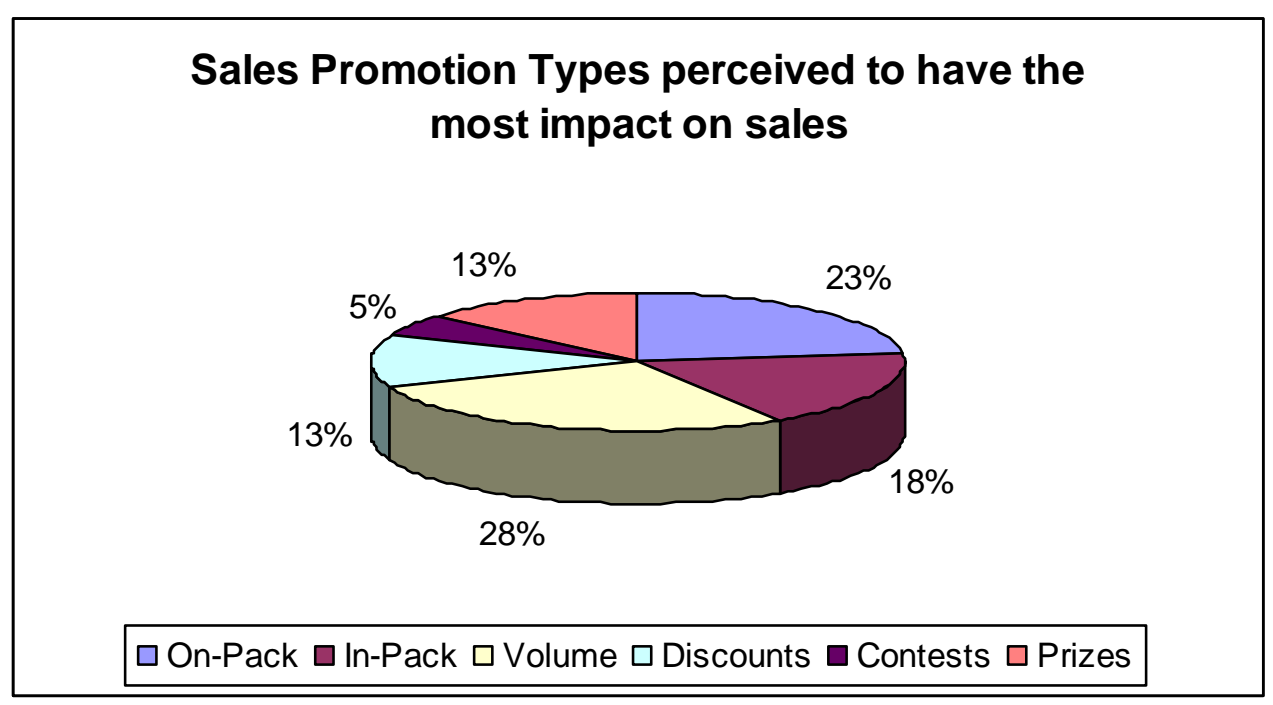

As expected, over $80 \%$ of the marketing executives in the survey admitted to not being able to measure ROI metrics of all their marketing campaigns, with $67.1 \%$ admitting only to be able to measure about $10 \%$ of their yearly campaigns, although the majority $(57.2 \%)$ mentioned they had all the necessary information.

\section{METHODOLOGY}

To evaluate any promotion, it is necessary to be able, in financial terms, to predict the promotional lift required to achieve an attractive ROMI, as well as to calculate the final results. In this paper, the first shall be called the "quick test" and the latter, the "post-mortem" analysis. For both, the following metrics have to be defined:

- Investment: This is the sum of all costs related, directly or indirectly, with the promotion. Not only fixed investment, but also costs of opportunity, such as price discounts or diminished profit margins are a part of this metric.

- Desired ROMI: This constitutes the rate of return determined by the company as their minimum expected return, or hurdle rate. This ROMI differs greatly from one company to the next, depending on its risk aversion. A useful rule of thumb is to set the desired ROMI at least 3.5 times the risk-free market rate.

- Required Results: These are the additional sales related to the promotion, but translated into the profits the promotion produces for the company. The required results must offset the investment as well as generate the desired ROMI.

- $\quad$ Average Transaction: This represents the financial sales results expressed, not in monetary terms, but in the company's stock keeping unit'.

- Profits Generated: This is the amount of the profit generated by each average transaction of the promotion (i.e., by each SKU or stock keeping unit sold).

\footnotetext{
${ }^{9}$ In the case of beverage companies, this metric is normally the case unit sold to the POP owners. In the pharmaceutical industry, it is often the amount of prescription generated by a normal treatment or by a new physician.
} 


\section{Quick Test}

In a world in which the marketing teams are staffed by highly creative, but often non-financial oriented staff, the quick test is designed to easily calculate the increase of sales or promotional lift required to achieve the desired ROMI. As shown in Table 1, this allows the decision maker to determine the realistic or unrealistic nature of the promotion.

\section{Table 1: Quick Test}
Promotion:
Details of Investment:
Current Base Line:
$\$$ SKU
Investment:
Desired ROMI:

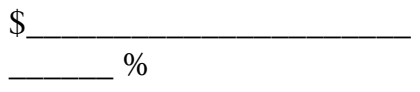
Required Results:
$\$$ Average Transaction: Profit Margin: $\$$ Profit Generated:

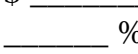 (per SKU)
Required Results in Units: Number of POP: $\$ \_$(per SKU)
Duration of Promotion: SKU per POP per Month: \#
$\%$ Increase in Sales: $\%$ applied, the quick test allows one to determine:
1. $\quad$ Required Results = Investment $\mathrm{x}$ 1Desired ROMI
2. $\quad$ Profit Generated $=$ Average Transaction $x$ Profit Margin
3. Required Results in Units $=$ Required Results/Profit Generated
4. $\quad$ SKU per POP per Month $=$ Required Results in units/\# POP/Duration of Promotion
5. $\%$ Increase in Sales $=($ SKU per POP per Month/Base Line Sales $) \times 100$ (expressed in profits)

Once knowing the investment of the promotion, the desired ROMI, the base line sales, the average transaction, the profit margin, the duration of the promotion, as well as the number of POP in which it will be

\section{Example}

A company wants to invest US $\$ 30,000$ in a promotion, targeting via a coupon valid in the nine existing POP establishments, and desires a minimum ROMI of $18 \%$. The service they provide costs US $\$ 660$ under a yearly contract with a profit margin of $42 \%$. Currently the company has an average of 320 service contracts per POP and the intended duration of the promotion is two months.

1. $\quad$ Required Results $=\$ 30,000 \times 1.18=\$ 35,400$

2. $\quad$ Profit Generated $=\$ 660 \times .42=\$ 277.20$

3. $\quad$ Required Results in Units $=\$ 35,400 / \$ 277.20=127.7$ SKU

4. $\quad$ SKU per POP per Month $=127.7 / 9 / 2=7.1 \mathrm{SKU}$

5. $\%$ Increase in Sales $=7.1 \mathrm{SKU} / 320 \mathrm{SKU}=2.22 \%$ 


\section{Post Mortem}

As mentioned, the quick test is to evaluate the feasibility of the promotion and to predict the required promotional lift to ensure the desired rate or return; but promotions have to be evaluated, not only before the event, but certainly after the promotion has expired, to determine the real ROMI obtained. The calculation is shown in Table 2.

Table 2: Post Mortem

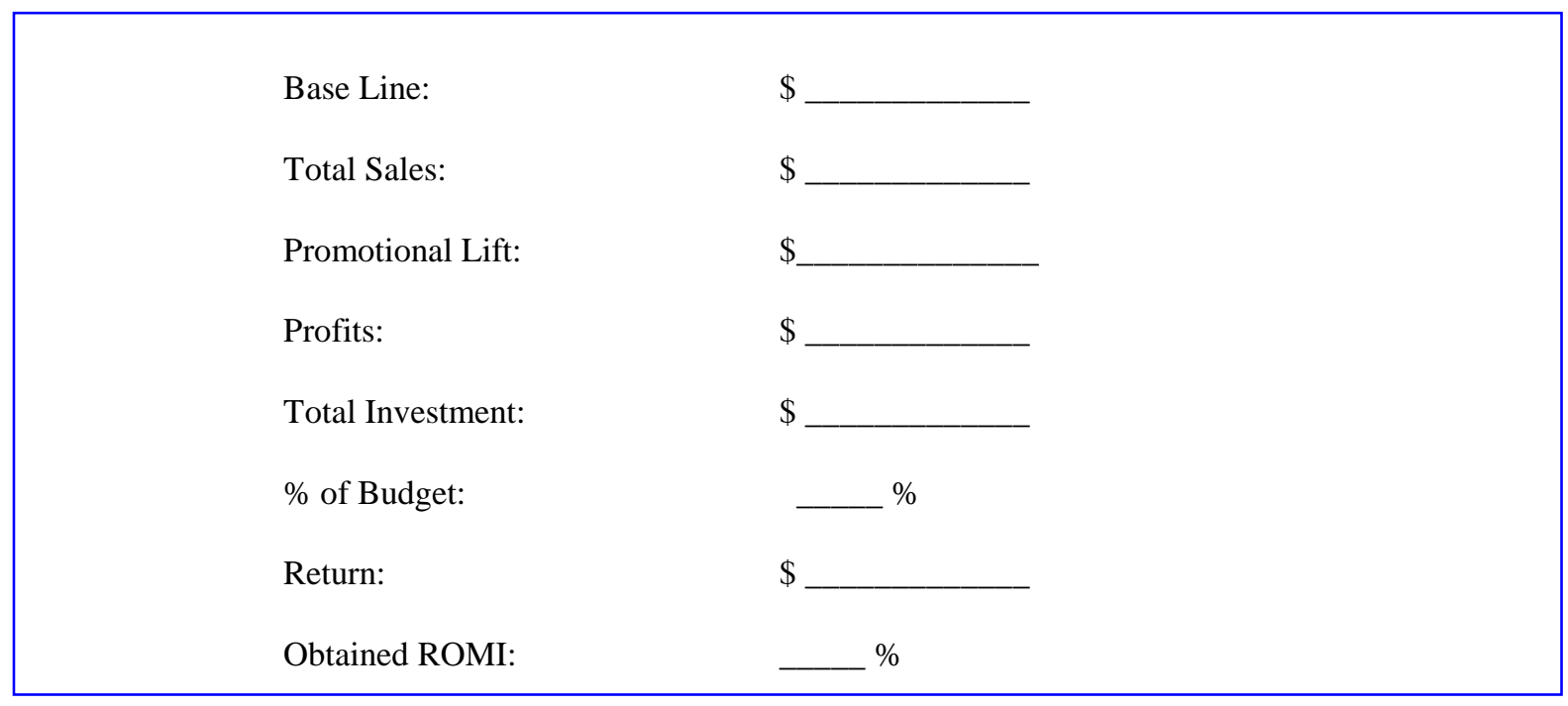

Where $^{10}$

- $\quad$ Return = Profits - Total Investment

- $\quad$ Obtained ROMI = Return/Total Investment

\section{Example (Continued)}

In the example, after the promotion has expired, the real sales figures allow to make the post-mortem analysis. The real sales amounted to 142 service contracts at the US $\$ 660$ rate, providing a profit for the company of US $\$ 39,362.40$. Thus,
- $\quad$ Return $=$
$\$ 39,362.40-\$ 30,000=\$ 9,362.40$
- $\quad$ Obtained ROMI =
$(\$ 9,362.40 / \$ 30,000) \times 100=31.2 \%$

As shown in the example, the minimum desired ROMI was surpassed and the real rate of return resulting from the promotion is $31.2 \%$.

\footnotetext{
${ }^{10}$ LENSKOLD, D. James. (2003). "Marketing ROI : The Path to Campaign, Customer, and Corporate Profitability". McGrawHill. U.S.A.
} 


\section{CASE STUDY: FEMSA}

Coca-Cola FEMSA is the largest Coca-Cola bottler in Latin America and the second largest in the world, accounting for one out of every ten Coca-Cola products sold globally. The company began operations in 1890 with the founding of a brewery in Monterrey, Mexico. Today, over a century later, it has grown from a brewer into a complete beverage company with integrated soft drink, beer, and retail operations.

It's core business is represented by soft drinks, a division that accounts for $56 \%$ of operating profits (in the year 2006, the company reported operating revenues of US \$11.6 billion with US \$1.6 billion in operating income), and in which they have over 70 brands, including the whole Coca-Cola line. Their distribution reaches more than two million points of sale throughout Latin America and is divided in the home market segment and the on-premise segment, which includes all food and entertainment establishments.

In Mexico, the 250,000 plus top accounts, whether on-premise or home market, are attended by the channel division that manages around 300 different promotions per year. Ironically, before the intervention, no financial analysis was being made before or after each promotion; thus, there was no true knowledge of which promotion had been a success or failure.

For the Business Plan (or BP 2008), ROMI analyses were being implemented for the first time, allowing to evaluate via the quick test, the feasibility of the proposed promotion before their deployment in the field. A $40 \%$ desired ROMI was established to measure each promotional idea and a promotional lift of no more than 5\% was placed as a realistic possible impact for any particular promotion (on the basis of market growth and penetration).

With these guidelines, any proposed promotional idea that looked good on paper was passed through the quick test. Promotions that needed a promotional lift of over $10 \%$ of sales were immediately eliminated due to their unrealistic nature. Promotions that required a promotional lift between 5 and $10 \%$ were revised to detect if the required investment could be reduced to lower that percentage. Finally, promotional ideas that only required a below 5\% promotional lift and produced the 40\% desired ROMI were included in the BP 2008.

An example of a promotional campaign for the mid market segment can be seen in Table 3, considering an average transaction measured in Unit Cases of US $\$ 3.5$ and a profit margin of 30\%, and with the promotion having effect throughout the year, in which:

- $\quad$ The required results equal US $\$ 2,142,000$ or Total Investment x 1Desired ROMI.

- $\quad$ Profits Generated per SKU or CU equals US \$1.05 or Average Transaction x Profit Margin.

- $\quad$ Required Results in Units equal 2,040,000 CU or Required Results/Profits Generated.

- Units per POP per Month result in 4.3 CU or Required Results in Units/\# of POP/12 months.

- $\quad$ Finally, the $\%$ of Increase of Sales equals $2.3 \%$ or Units per POP per Month/Base Line Sales. 
Table 3: Quick Test

\begin{tabular}{|c|c|}
\hline Promotion: & BP 2008 Mid Market \\
\hline Description: & $\begin{array}{l}\text { Invest in } 35 \% \text { of the total customer base of } \\
113,000 \text {, which currently average monthly sales of } \\
190 \mathrm{CU} \text {, in communication, exhibition and } \\
\text { refrigeration on-the-go. }\end{array}$ \\
\hline Total Investment: & US $\$ 1,530,000$ \\
\hline Desired ROMI: & $40 \%$ \\
\hline Required Results: & US $\$ 2,142,000$ \\
\hline Average Transaction: & US $\$ 3.50($ per CU $)$ \\
\hline Profit Margin: & $30 \%$ \\
\hline Profits Generated: & US \$1.05 (per CU ) \\
\hline Required Results in Units: & $2,040,000$ of $\mathrm{CU}$ \\
\hline Number of POP: & 39,550 \\
\hline Units per POP per Month: & $4.3 \mathrm{CU}$ \\
\hline$\%$ increase of sales: & $2.3 \%$ \\
\hline
\end{tabular}

As shown in the example evaluation of the promotion, it falls in the guidelines established by the company, and, as such, was included in the BP for 2008. Of course, a post-mortem evaluation will have to be done at the end of the year to identify if the desired ROMI was met or even exceeded.

One certainty is unquestionable in that FEMSA, for the first time, will be able to say with a high level of confidence, which of the 300 different promotions executed in the fiscal year 2008 were successes and which turned out to be failures, making the creation of the Business Plan 2009 a much easier task.

\section{AUTHOR INFORMATION}

Nico Schinagl Waller has a PhD in Applied Management from the Universidad Anahuac del Sur, Mexico, led by Dr. Carlos Barber Kuri. He is a published author with his book, "The Sales Specialist", as well as articles in magazines, such as Mundo Ejecutivo and the Harvard Business Review LATAM edition. His main focus is to give sales and marketing consulting to companies in the Latin American region, as well as be the president of the Sales Specialist Club, a community of practice of more then twelve thousand members to share information and create new know-how about sales in Latin America. 
NOTES 